\title{
A Study on English Acquisition from the Perspective of the Multimodal Theory
}

\author{
Huaiyu $\mathrm{Mu}$ \\ Inner Mongolia University, China
}

\begin{abstract}
This paper aims to explore watching English movies as an effective way of learning English for English learners to improve their English level on the basis of theoretical framework of the multimodal discourse analysis. Watching English movies can greatly stimulate English learners' interest in learning English. In the process, they can get dual stimulation from visual and auditory senses by using the visual modality, auditory modality and tactile modality. Learners may acquire English knowledge in a relatively authentic language environment, and by listening to and imitating idiomatic English expressions, they can acquire cultural knowledge, further understand the culture, people's way of thinking and humanistic spirit and values of English-speaking countries, and thus improving their English level and ability of cross-cultural communication.
\end{abstract}

Index Terms—multimodal theory, English learning, English movies, cross-cultural communication

\section{INTRODUCTION}

The purpose of learning a foreign language is to use it to communicate with other people, learning English is no exception. Among the comprehensive abilities of listening, speaking, reading, writing and translation in learning English, the abilities of listening and speaking are very important skills, and play a very important role in learners' work and social life in the future. Nowadays, multimedia technology has been widely used in teaching, especially in foreign language teaching. Multi-modal teaching mode integrates the static resources and the dynamic resources into the teaching process by using different media, giving the students a full range of multisensory experience, causing multi-level association. According to Gu YG's (2007) multimodal foreign language learning mode, the shift between different modalities can stimulate the brain to produce a stronger memory and thus improve the understanding. Among the five communication modalities, namely the visual modality, the auditory modality, the tactile modality, the olfactory modality and the gustatory modality, the visual and aural modalities have the closest relationship with the discourse analysis (Zhu YS, 2007).

The interaction between normal people is multimodal (Gu YG, 2007). A good English movie covers the major factors in language learning such as pronunciation, intonation, rhythm, wording, thought, feeling, etc. While the learners appreciate English movies, they can get dual stimulation from the visual and auditory senses. In addition, it can help them better understand a wide range of knowledge, such as the significance of the film's theme, historical background, social connotation, mainstream values, plots and customs, natural and humanistic environment and so on through observing the characters' facial expressions, postures, gestures. By listening and imitating the idiomatic English expressions in the movies, the learners can internalize the English language in a subtle way in the process.

The purpose of language learning is to communicate, but communication is not only a linguistic phenomenon, but also a cultural, even a cross-cultural phenomenon. Language is a part of culture, and it plays an important role in culture. On the other hand, language is influenced by culture and reflects culture. It can be said that language reflects the characteristics of a nation, it not only contains the nation's historical and cultural background, but also contains its values, life style and way of thinking. Language is the carrier of culture, learning a foreign language is also to learn and adapt to a foreign culture (Liu RQ, 1999). Language learning is the process of cultural integration. Without rich cultural deposits, we can not express ourselves clearly and accurately, and without corresponding background knowledge, we will fall into embarrassing and unfavorable situations. Therefore, foreign language learning must be combined with cultural learning. Because China and Western countries have great differences in social system, ideology, way of thinking, cultural concepts, social customs, historical and cultural traditions and so on, these differences will certainly be embodied in the language. In order to overcome a series of problems caused by the differences, in the process of cultivating their practical ability of using English, English learners should grasp the knowledge about cultural background as much as possible so as to improve their cultural accomplishment, develop their abilities of linguistic applying and information communicating, and thus, promoting their ability of cross-cultural communication.

\section{LITERATURE REVIEW}

Halliday (1985) holds that in the specific social circumstances, people always use a variety of symbolic resources to complete the construction of meaning, and different semiotic resources constitute multimodality (Kress \& Van Leeuwen, 2001). The so-called "modality", according to the Forceville's (2009) point of view, refers to "the semiotic system that 
can be explained by the specific perceptive process"(p.22). It can be specifically divided into the following categories: image symbols, written symbols, verbal symbols, gestures, sound, smell, taste, touch (Forceville, 2009). LeVine and Scollon (2004) think that multimodality refers to a variety of modes used in communication, such as speech, color, taste, image, etc. Hu ZL (2007), Gu YG (2007), Zhang DL (2009) and Zhu YS (2008) and so on think that the use of more than two senses in the interaction constitutes multimodality. The theory of multimodal discourse analysis sprung up in 1990s. In 1996, the New London Group first advocated multimodality to be applied into language teaching process, that is, multiple semiotic modalities (such as language, images, music, Internet and the like) should be introduced into the teaching process, motivating students to participate in learning with their multiple senses, stimulating students' memory and association, enhancing the cognitive effect. Helgesen (2003), Rost (2002) and Richards Schmidt (2002) and so on define listening as an active process of meaning construction, and the hearer does not just simply decode what he or she hears, but also will actively get the information from the signals that they see or hear and then "associates it with the knowledge they have" (Rubin, 1995, p.3-15). In China the research about multimodal discourse analysis began in 2003 (Li ZZ, 2003), many scholars have combed the origin of the research on multimodal in China and its research approaches and research fields (Li ZZ, Lu DY, 2012; Li HB, 2013; Dai SL, 2013; Feng DZ, 2014). Zhang Z (2013) thinks the cultivation of multiple ability of reading and writing should be stressed. Lv MJ and Mu WJ (2014 ) hold through their research that the multimodal teaching has a positive effect on college students' ability of comprehension and recall of information in English reading, and it can also strength students' ability of the construction of discourse meanings due to the rich input of information and the stimulus of different sensory organs.

Therefore, listening teaching is the first step in applying multimodality into teaching, and also is the breakthrough to achieve the target of multiliteracy (Li X, Li MY \& Wang JZ, 2012).

English movies can fully motivate the comprehensive uses of learners' multiple senses, improving their memory efficiency. In the process of watching English movies, learners' senses of hearing and sight are fully mobilized, and the brain has been in a more excited state all the time, and in this way, the language, culture and other information in the movies will quite naturally be input into the learners' brain. So, students can learn English with the perfect combination of the storylines, scenery and characters and under the condition of sound, images and manners in the movies, and practice oral English in the movies' scenes, exert their subjective initiative, and the level of listening and speaking will be improved unconsciously.

\section{The CHARACTERISTICS AND FunCTIONS OF ENGLISH VisuAL-AUDiO MATERIALS}

\section{A. English Movies Can Stimulate Students Interest}

The affective filter hypothesis proposed by Krashen, linguistics educator, thinks that affective filtration is a fictional wall between learners and language input. When a learner's learning motivation is not strong, he has little interest in learning, and when he is in anxious mood, affective filtration is in open state, which hinders the language from inputting (Krashen S, 2001). Based on this hypothesis, in the process of learning English, we should adopt lively learning ways to improve and stimulate students' interest in learning, and create a relaxed atmosphere for learning. English movies integrate much information such as pictures, voice, plots and the like, and truly reflect life and cultural customs of the English-speaking countries, greatly stimulate the students' interest in learning English. It can be said that English movies provide the learners a moving, changing, vivid and relaxing surroundings of studying English. As Hill (1991) thinks that the film is very attractive, and they stimulate one's interest greatly, and make them produce a sense of participation in the learning process.

\section{B. It Is Helpful for Learners to Fully Understand the Cultural Background and Cultural Traditions of English-speaking Countries and to Cultivate the Learners'Ability of cross Cultural Communication}

Learning a language does not only mean learning the language's grammatical knowledge, developing language skills, but also mastering the rich culture of the language. C. Kramsch, professor at the University of California, has pointed out in his works: Mastering a language does not only mean learning the language itself. In the process of learning a language, cultural knowledge of the target language is not only important in the cultivation of communicative competence, but also is one of the requirements of education itself (Kramsch. C, 2001). The movie is a mirror, and it can reflect every respect of social life and culture of a country and a nation, expose some social problems in the reality. The customs, people's life style and values of a country can be reflected in the story of a movie and actors' lines. By appreciating English movies learners can be aware of the differences between Chinese and Western cultures, broaden their horizons, enrich their cultural knowledge, reduce prospective cultural conflicts arising in the process of communication.

\section{It Is Beneficial for Learners to Enhance the Ability of Flexible Expression and Accumulates the Vocabulary}

Language is a tool, and the purpose of learning a language is to use this tool to express our wishes and demands, achieve the purpose of communication. Vocabulary, as one of the three major elements of language, is the most basic component of language expression. In English learning, it is impossible to have strong skills of reading and communication without accumulation of a certain amount of vocabulary. A good English movies can cover the major elements such as the pronunciation, intonation, rhythm, wording, thoughts, feelings and so on. While the learners 
appreciate English movies, they can get dual stimulation from the visual and auditory senses. By listening and imitating the standard English expressions in the movies, the learners can internalize the English language in a subtle way in the process.

The dialogues in English movies are very standard and very rich in content, and expressions of many classic sentences embody the very high wisdom and deep connotation of language, such as the line in the classic movie Forrest Gump, "My mama always said life is like a box of chocolates. You never know what you are gonna get". The purpose that we watch the movies is, on the one hand, to appreciate the storylines, and more important, is to carefully understand the skills of language expression through this way, learning to flexibly use the grammatical knowledge that we have mastered. Vocabulary is the foundation of language expression, and many English words have more than one meaning, while we usually memorize the common meanings, so we can acquire the other meanings of the words by watching English movies, and thus enriching our English vocabulary.

\section{Provide Idiomatic Spoken English and Authentic Contexts}

In the daily life, learners have little opportunities to contact English native speakers and realize their speech habits and lifestyle. And movies stem from life, the language and communicative scenes displayed in English movies are the same ones that English native speakers live in, making learners to have the feeling of being personally on the scenes. Vivid and lifelike lines, pictures and scenes make learners feel the standard English without going abroad. In this way, learners can acquire useful and standard English expressions in a very natural way, and apply them in the practical communication.

English movies display clear and standard pronunciation and life-based language, including some frequently used slang, idioms, etc. These lively and vivid lines with different styles provide authentic listening materials to learners. The characters in movies usually speak at a normal speed, which, on the one hand, makes learners adapt to and imitate standard English used in the authentic situations, so that they can put what they have learned into practice; on the other hand, which makes learners fully understand formation of constructions and reductions commonly used in spoken English and fall into the right habits of listening English, gradually familiar with American and British accents. Learners can contact the accents and registers of speech with pure pronunciation and normal speed of different people from English-speaking countries, thus, getting rid of the restriction of the "written language", which is helpful to the listening comprehension in the cognitive process.

\section{Selection of Visual-audio Materials}

\section{A. First of All, We Should Choose Films with Healthy Contents and Positive Themes}

The movies are the carrier of morality and culture, and they will have a subtle influence on learners' values and outlooks on the world. Therefore, we should choose the movies with positive themes, healthy and noble content. These movies are beneficial to improve the learners' language performance and increase their understanding of different cultures; to set up the correct morals and values and cultivate their thinking ability. For example, Forrest Gump makes us learn to be kind, honest, optimistic and working hard and other excellent virtues; Lion King provokes learners' to think about the issues on life and death; The Pursuit of Happiness makes people ponder over what the real happiness is; Crash makes people better understand American multicultural and so on.

\section{B. Choose the Movies with a Moderate Rate of Speech and Standard Pronunciation}

In the process of watching English movies, learners not only can cultivate their own sensitivity to English, correct their nonstandard and even wrong pronunciation, but also can improve their listening and speaking ability. The English movies with moderate rate of speech, standard pronunciation and beautiful melody not only provide visual and auditory enjoyment for English learners, but also an authentic language environment for them, as if they were personally in the movies. In this way, learners will acquire useful and idiomatic English expressions in a very natural state and apply them to the practical communication. "Learners will also easily experience the fun of learning English, and listen to the idiomatic spoken English in the process of appreciating English movies, therefore, learning effect will be much better" (Williams M\& Burden R. L, 2000, p.50-51).

\section{Choose the English Movies with a Large Amount of Information and Being Close to Life}

The purpose that we watch English movies is very clear, that is to improve the skills of English listening and speaking through this way. Therefore, when we choose English movies, we should choose the ones with a large amount of information and rich conversation. The English movies with content close to life will provide a more authentic language environment for the learners, because the language close to life is the most useful to the learners and also is the most frequently used in the daily life. Watching this kind of movies will also help us to understand the customs, ways of thinking and communicative norms of English-speaking countries, and further understand the habits and skills of speaking English.

\section{ACQuisition Process under the Perspective of the Multimodal Theory}

\section{A. Make Notes}


On the one hand, it is difficult to understand the dialogues in English movies; on the other hand, there are some good expressions appearing in the movies, especially some good dictums and sentences. When we watch the movies, we will have an impression of these expressions, but we will also forget them after a long time, which requires us to repeatedly watch and listen, write down some useful ways of expression, sentence structures and the scenes in which they are used while we watch the movies, and choose some classic extracts to practice so as to enhance understanding and memory and make ourselves use accurately the ways of expression we have learned. In this way, our ability of oral expression will be continuously improved. In this process, we should pay attention to intensive listening, and repeatedly read the key words which have been written down before and the classic lines of the characters until we can blurt them out, and use them repeatedly in the daily life. Only in this way can the sentence structures be transformed into our own knowledge.

\section{B. Learn the Cultures Contained in English Movies}

Language and culture are intimately tied together. It is impossible to learn a foreign language without learning its culture. Language is both the carrier and container of culture. One of the best ways to learn it is through watching English movies. Language in movies is from real life, it embodies and represents the cultural reality. The forms of language and social cultural contexts provided by a variety of movies' materials can cultivate learners' ability to recognize cultural differences, stimulate their motivation of the assimilation so as to make them combine knowledge and culture organically. In addition, the movie is a disseminator of culture. We cannot rely on using language to analyze thoroughly the development of storylines or the changes of relationship between characters, among which, there are too many aspects different from Chinese thinking ways. This requires us to learn the background knowledge about Western culture, and then analyze point by point on the basis of understanding, summarize unceasingly, and feel the differences of the values and thinking ways of China and Western countries with the heart. Only through the comprehensive understanding of Western history, culture and the like can language become the real communication, improving learners' intercultural communicative competence.

\section{Times of Watching English Movies}

If we want to promote English learning through watching English movies, it does not matter how many movies have been watched, but how much knowledge we have acquired. Therefore, in the first time, learners should watch an English movie without English subtitles so as to has a general understanding of the whole scene of the movie, grasp the outline and background of the story; in the second time, they should watch with English subtitles to realize which scene, content and words they don't understand; in the third time, they should to watch with Chinese subtitles and think carefully about what they do not understand; in the fourth time, they should watch with English subtitles again and learn by heart the typical sentences and words and expressions with distinctive features, and then read and imitate them while watching on the basis of fully understanding the whole movie; in the fifth time, they should watch without subtitles. In the process of watching English movies, the learners should try to imitate the pronunciation and intonations of characters in the movies, through which they not only can practice their listening comprehension but also improve their oral English. If they have time or energy, they may watch the movie again in two days so as to achieve the effect of consolidation. During the whole process, the modal shift occurs namely, the shift from the input of the auditory modality to the motive modality and writing modality including visual nerves, vocal organs and limb motion can enhance learners' internalization of the knowledge they have learned, and help them to shift more input into in-take (Long YF \& Zhao P, 2009).

\section{CONCLUSION}

English movies are close to life and have rich content and authentic scenes, are a vivid reproduction of the cultural life of Western countries, valuable materials for language learning, can fully motivate learners' enthusiasm, improve their interest of learning, and can also encourage them to fully understand the customs and culture of Western countries, help them cross cultural barriers, keep in mind the language knowledge so as to improve the practical ability of speaking English. In the process of watching English movies, all the learners' senses including the senses of hearing, sight and touch and the like are motivated, exerting their subjective initiative. They can learn idiomatic English as if they were personally on the scene and experience the rich and colorful cultures from foreign countries. All this will has a great influence on the improvement of learners' linguistic application, especially the abilities of listening and speaking. Obviously, appreciation of English movies is a very effective means of learning English and can effectively improve English learning.

\section{REFERENCES}

[1] Dai SL. (2013). Origin and Progress of Research on Multimodal Discourse. Foreign Language Research, 2, 17-23.

[2] Feng DZ, Kay O' Halloran \& Zhang DL. (2014). Advances and Frontiers of Multimodal Analysis. Contemporary Linguistics, 1, 88-89.

[3] Forcecille C. (2009). Non-verbal and Multimodal Metaphor in a Cognitivist Framework: Agendas for Research. In C. Forcecille \& E. Uris-Aparisi (Eds.), Multimodal Metaphor---Applications of Cognitive Linguistics. New York: Mouton de 
Gruyter, 22.

[4] Gu YG. (2007). Learning Analysis of Multimedia and Multimodality. Language Teaching, 2, 3 - 12.

[5] Halliday, A. M. K. (1985). An Introduction to Functional Grammar. London: Edward Arnold.

[6] Helgesen, M. (2003). Listening. In D. Nunan, Practical English Language Teaching. New York: McGraw-Hill, 22-26.

[7] Hill B. (1991). Making the Most of Satellites and Interactive Video. London: Information Language Teaching and Research.

[8] Hu ZL. (2007). Multimodalization in the Research of Social Semiotics. Language Teaching and Research, 1, $1-10$.

[9] Kramsch. C. (2001). Environment of Language Learning and Culture. Shanghai: Shanghai Foreign Language Education Press.

[10] Krashen S. (2001). The Input Hypothesis: Issues and Implications. Shanghai Foreign Language Education Press, 25-36.

[11] Kress, G. \& T. van Leeuwen. (2001). Multimodal Discourse: The Modes and Media of Contemporary Communication. London: Arnold.

[12] Li HB. (2013). The Research Approaches and Fields of Multimodality. Journal of Xian International Studies University, 3, $21-25$.

[13] Liu RQ. (1999). On College English Teaching. Beijing: Foreign Language Teaching and Research Press, 177.

[14] Li X, Li MY\& Wang JZ. (2012). On the Effectiveness of the Multimodal Autonomous Listening Model. Journal of PLA University of Foreign Languages, 6, 60.

[15] Li ZZ. (2003). The analysis on the social symbols of multimodal discourse. Foreign Language Teaching and Research Press, 5, $1-8$.

[16] Li ZZ\& Lu DY. (2012). Multimodal Semiotics: Theoretical Basis, Research Approaches, and Developing Prospects. Foreign Language Teaching and Research Press, 2, 1-8.

[17] Long YF\& Zhao P. (2009). Research on Interaction of Metacognitive Strategies of College English Listening Teaching and Multimodality. Foreign Language Research, 7, 58 - 62.

[18] Lv MJ and Mu WJ. (2014). A Research on the Effect of the Multimodal Teaching on the College Students' Reading Ability. China Educational Technology, 335, 129-132.

[19] Richards, J. C. \& R. Schmidt. (2002). Longman Dictionary of Language Teaching and Applied Linguistics. London: Longman.

[20] Rost, M. (2002). Teaching and Researching Listening. Harlow, UK: Pearson Education /Longman.

[21] Rubin, J. (1995). An Overview to A Guide for the Teaching of Second Language Listening. In D. Mendelsohn \& J. Rubin. A Guide for the Teaching of Second Language Listening. San Diego: Dominie Press, 3-15.

[22] Scollon, Ron \& Levine, Philip. (2004). Multimodal Discourse Analysis as the Confluence of Discourse and Technology. Washington DC: Georgetown University Press.

[23] Williams M, Burden R. L. (2000). Psychology for Language Teaching. Beijing: Foreign Language Teaching and Research Press, 50-51.

[24] Zhang DL. (2009). Exploration on the Theoretical Frame of Multimodal Discourse Analysis. China Foreign Language, 1, 30 24.

[25] Zhang Z. (2013). Multimodal Literacy Development in Classroom Ecosystem. Jinan: Shandong University Press.

[26] Zhu YS. (2007). The Theoretical Basis and Research Methods of Multimodal Discourse Analysis. Foreign Language Research, 5, 83-86.

[27] Zhu YS. (2008). Research on Multiliteracy and Its Revelations for Teaching Reform in China. Foreign Language Research, 4, $14-10$.

Huaiyu Mu was born in Hohhot, the Inner Mongolia Autonomous Region, China in 1978. He received his MA degree in foreign linguistics and applied linguistics from Inner Mongolia University, China in 2002.

$\mathrm{He}$ is currently a lecturer in the Foreign Languages College, Inner Mongolia University, Hohhot, China. His research interests include translation studies and American literature. 